\title{
Polyphyllin I and VII potentiate the chemosensitivity of A549/DDP cells to cisplatin by enhancing apoptosis, reversing EMT and suppressing the CIP2A/AKT/mTOR signaling axis
}

\author{
FEIFEI FENG ${ }^{1 *}$, PENG CHENG $^{2 *}$, CHAOCHAO WANG ${ }^{1}$, YONGBIN WANG $^{1}$ and WEI WANG ${ }^{1}$ \\ Departments of ${ }^{1}$ Respiratory Medicine and ${ }^{2}$ Neural Medicine, The Second Hospital \\ of Shandong University, Jinan, Shandong 250033, P.R. China
}

Received March 29, 2019; Accepted August 14, 2019

DOI: $10.3892 / 01.2019 .10895$

\begin{abstract}
Poor response and resistance to cisplatin (DDP)-based chemotherapy frequently leads to treatment failure in advanced non-small cell lung cancer (NSCLC). The underlying molecular mechanism is extremely complex and currently remains unclear. The overexpression of cancerous inhibitor of protein phosphatase 2A (CIP2A) indicates poor prognosis and promotes the epithelial-to-mesenchymal transition (EMT) and metastasis. The EMT has been reported to promote drug resistance in numerous previous studies. CIP2A and its downstream protein kinase B (AKT)/mammalian target of rapamycin (mTOR) pathway also plays a role in mediating DDP resistance. Polyphyllin I (PPI) and polyphyllin VII (PPVII) are natural components extracted from Paris polyphylla that display anti-cancer properties. In the present study, the chemosensitizing effects of PPI and PPVII were investigated in the DDP-resistant NSCLC cell line A549/DDP, as well as the underlying molecular mechanisms. The results demonstrated that PPI and PPVII could significantly inhibit cell proliferation and enhance the sensitivities of A549/DDP cells to DDP. When assessing the underlying molecular mechanism, it was revealed that PPI and PPVII enhanced DDP-induced apoptosis in A549/DDP cells via p53 upregulation and the caspase-dependent pathway. Furthermore, PPI and PPVII reversed the EMT and suppressed CIP2A and its downstream AKT/mTOR signaling cascade in A549/DDP cells. Overall, the results from the present study demonstrated that PPI and PPVII may function as chemosensitizers by
\end{abstract}

Correspondence to: Professor Wei Wang, Department of Respiratory Medicine, The Second Hospital of Shandong University, 247 Beiyuan Street, Jinan, Shandong 250033, P.R. China

E-mail:sducp@qq.com

*Contributed equally

Key words: polyphyllin I, polyphyllin VII, cisplatin-resistance, p53, epithelial-mesenchymal transition, cancerous inhibitor of protein phosphatase $2 \mathrm{~A}$ enhancing apoptosis via the p53 pathway, reversing EMT and suppressing the CIP2A/AKT/mTOR signaling axis, and the combination with DDP may be a promising strategy for the development of new therapeutic agents.

\section{Introduction}

Lung cancer is the leading cause of mortality among patients with cancer worldwide and non-small cell lung cancer (NSCLC) is the major type of lung cancer, accounting for nearly $85 \%$ of lung cancer cases (1). Most patients with NSCLC are diagnosed in the advanced phase and the 5-year survival rate is $<5 \%$ despite advances in treatment (1). Chemotherapy plays a critical role in lung cancer treatment (2). Cisplatin (DDP) is one of the first-line chemotherapeutic agents used to treat NSCLC. However, the majority of patients suffer from DDP resistance, leading to treatment failure, limiting its clinical application (3). In addition, DDP-based regimens are frequently associated with dose-associated toxicity, which results in decreases in drug tolerability and therapeutic efficacy (4). Thus, investigating the underlying molecular mechanism of DDP-resistance and developing new therapeutic agents that are more effective and less toxic in sensitizing NSCLC to chemotherapy is urgently required.

The epithelial-to-mesenchymal transition (EMT) has been reported to promote drug resistance in a number of previous studies (5-7) and thus, ongoing research has focused on investigating ways to reverse or delay the EMT to prevent drug resistance (6). Cancerous inhibitor of protein phosphatase $2 \mathrm{~A}$ (CIP2A) is a novel human oncoprotein that is overexpressed in numerous types of human malignancy and is a predictor for poor prognosis, including NSCLC (8-10). CIP2A inhibits protein phosphatase $2 \mathrm{~A}$ (PP2A) tumor suppressor activity and facilitates tumor growth, progression, metastasis, apoptosis and drug resistance in numerous different types of cancer $(9,10)$. In addition, CIP2A facilitates the EMT process via the mitogen-activated protein kinase (MEK)/extracellular signal-regulated kinase-1 (ERK) pathway (11). CIP2A also mediates the anticancer effects of numerous compounds and its potential role in mediating the resistance of cancer cells to numerous chemotherapeutic agents has been confirmed (12-15). Notably, CIP2A mediated protein 
kinase B (AKT) phosphorylation $(14,16)$ and the AKT downstream mammalian target of rapamycin (mTOR)/p70S6K1 pathway plays roles in mediating DDP resistance in lung cancer (17). Therefore, the CIP2A signaling axis may be an effective target in reversing DDP resistance and improving the response to DDP-based therapy in NSCLC.

Rhizoma of Paris polyphylla (RPS), a traditional Chinese medicinal herb, has been widely prescribed by herbal practitioners to treat infection, hemorrhage, immune diseases and tumors (18). Polyphyllin I (PPI) and polyphyllin VII (PPVII) are two of the primary active components isolated from RPS, which exhibit strong anticancer effects in a number of different types of cancer by regulating the signaling pathways associated with proliferation, apoptosis and autophagy (19-27). Notably, PPI and PPVII have also been demonstrated to possess chemosensitizing effects in a number of different types of cancer (28-32). However, the effects of PPI and PPVII on DDP-resistant lung cancer cells remain unclear. In the present study, the chemosensitizing effects of PPI and PPVII on A549/DDP cells were investigated in vitro, alongside further investigation into the potential underlying molecular mechanisms.

\section{Materials and methods}

Cell culture and reagents. Human NSCLC cell lines A549 and DDP-resistant A549/DDP cells (OriGene Technologies, Inc.) were cultured in RPMI-1640 (Gibco; Thermo Fisher Scientific, Inc.) supplemented with $10 \%$ fetal bovine serum (Gibco; Thermo Fisher Scientific, Inc.) and penicillin (100 U/ml)-streptomycin $(100 \mathrm{mg} / \mathrm{ml})$ at $37^{\circ} \mathrm{C}$, with $5 \% \mathrm{CO}_{2}$. A549/DDP cells were cultured in RPMI-1640 with 1,000 ng/ml DDP (Sigma Aldrich; Merck KGaA). PPI and PPVII were purchased from Beijing Solarbio Science \& Technology Co., Ltd. Antibodies used in the present study were: anti-E-cadherin (cat. no. 3195T), anti-vimentin (cat. no. 12826S) anti- $\alpha$-smooth muscle actin (SMA; cat. no. 19245T), anti-CIP2A (cat. no. 14805S), anti-AKT (cat. no. 4691T), anti-phosphorylated AKT (p-AKT; cat. no. 4060S), anti-p-mTOR (cat. no. 5536T), anti-mTOR (cat. no. 2983T), anti-poly (ADP-ribose) polymerase 1 (PARP; cat. no. 9532T), anti-cleaved PARP (cat. no. 9542T), anti-p53 (cat. no. 2527T), anti-Bcl-2 (cat. no. 15071T), anti-Bax (cat. no. 5023T), anti-caspase-3 (cat. no. 14220T), anti-cleaved-caspase-3 (cat. no. 9664T) and anti-GAPDH (cat. no. 5174T), which were all purchased from Cell Signaling Technologies, Inc.

Cell proliferation and viability assays. Cells that had reached the logarithmic growth phase were adjusted to a cell density of $5.0 \times 10^{4} / \mathrm{ml}$ and $100 \mu \mathrm{l}$ was seeded in 96 -well plates at a density of $5.0 \times 10^{3}$ cells/well. Cells were allowed to adhere for $24 \mathrm{~h}$, after which the cells were treated with the indicated drugs and cultured for a further $24 \mathrm{~h}$. A total of $100 \mu \mathrm{l}$ sterile Cell Counting Kit-8 (CCK-8) solution (Dojindo Molecular Technologies, Inc.) was added to the culture medium of each well and incubated at $37^{\circ} \mathrm{C}$ for $2 \mathrm{~h}$, and the absorbance was measured at $450 \mathrm{~nm}$ using a microplate reader. The effect of each drug on the cell viability was calculated according to the following formula: Cell survival rate (cell viability) $\%=$ [optical density (OD) of dosing group A/OD of control group A] x100\%.
Annexin V-fluorescein isothiocyanate (FITC)/propidium iodide (PI) apoptosis analysis. Apoptotic cells were measured using an Annexin V-FITC Apoptosis Detection kit (BD Biosciences) according to the manufacturer's protocol. A549/DDP cells were treated with the indicated drugs for $24 \mathrm{~h}$ and then washed with PBS. The cells were resuspended in $500 \mu \mathrm{l}$ binding buffer, $5 \mu \mathrm{l}$ Annexin V-FITC and $5 \mu \mathrm{l}$ PI were added and the mixture was incubated in the dark at room temperature for $15 \mathrm{~min}$. The cells were then analyzed using a BD FACS Canto ${ }^{\mathrm{TM}}$ III flow cytometry device and Kaluza Analysis software (version 1.3; Beckman Coulter, Inc.). Early apoptotic cells were Annexin V-FITC $(+) /$ PI (-), while late apoptotic or necrotic cells were Annexin V-FITC (+)/PI (+).

Western blot analysis. Cells were washed twice with PBS and lysed with RIPA buffer (Beyotime Insititute of Biotechnology) according to the manufacturer's protocol. Using BCA protein concentration assay, lysates were normalized and protein samples were prepared with SDS-PAGE protein sample buffer (Beyotime Institute of Biotechnology) at a volume ratio of 4:1. Samples containing equal quantity of protein $(25 \mu \mathrm{g})$ were separated via SDS-PAGE (10\% gel) and then electro-transferred to polyvinylidene fluoride membranes (EMD Millipore) using a constant current of $200 \mathrm{~mA}$ for at least $2 \mathrm{~h}$ at $0^{\circ} \mathrm{C}$. The membranes were blocked with $5 \%$ non-fat milk made with Tris-buffered saline (containing $0.1 \%$ Tween 20 ) at room temperature for $1 \mathrm{~h}$, followed by incubation with the primary antibodies overnight at $4^{\circ} \mathrm{C}$ : anti-E-cadherin $(1: 1,000)$, anti-vimentin $(1: 1,000)$, anti- $\alpha$-SMA $(1: 1,000)$, anti-CIP2A $(1: 1,000)$, anti-AKT (1:1,000), anti-p-AKT $(1: 2,000)$, anti-p-mTOR $(1: 1,000)$, anti-mTOR $(1: 1,000)$, anti-PARP $(1: 1,000)$, anti-cleaved PARP (1:1,000), anti-p53 (1:1,000), anti-Bcl-2 (1:1,000), anti-Bax $(1: 1,000)$, anti-caspase-3 $(1: 1,000)$, anti-cleaved-caspase-3 $(1: 1,000)$ and anti-GAPDH $(1: 1,000)$. Then the membranes were washed and incubated with the corresponding secondary horseradish peroxidase-conjugated antibodies (1:2,500; cat. nos. ZB-2305 and ZB-2301; OriGene Technologies, Inc.) at room temperature for $1 \mathrm{~h}$. The bound antibody complexes were detected using the immobilon western chemiluminescent HRP substrate(cat. no. WBKLS0100; EMD Millipore) and analyzed using Quantity One software (version 4.6; Bio-Rad Laboratories).

Statistical analysis. All experiments were repeated at least three times and the data were processed using SPSS software (version 19.0; IBM Corp.). The relative expression levels were presented as the mean \pm standard deviation. Differences between data groups were evaluated for significance using one-way analysis of variance followed by the Tukey test. $\mathrm{P}<0.05$ was considered to indicate a statistically significant result.

\section{Results}

Characterization of A549 and A549/DDP cells. A549 and A549/DDP cells were exposed to different concentrations of DDP $(1-32 \mu \mathrm{g} / \mathrm{ml})$ for $24 \mathrm{~h}$ (Fig. 1A). The 50\% inhibitory concentration $\left(\mathrm{IC}_{50}\right)$ of DDP against A549 cells was $5.49 \mu \mathrm{g} / \mathrm{ml}$, while the $\mathrm{IC}_{50}$ of DDP against A549/DDP cells 
A

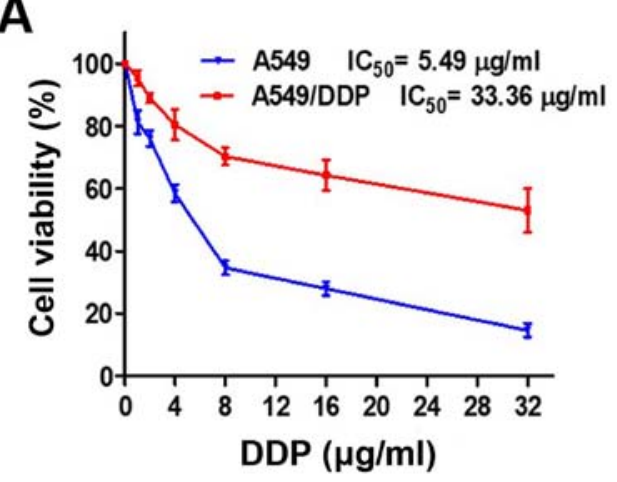

B

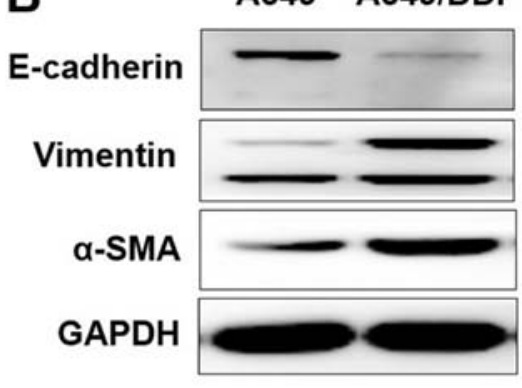

C A549 A549/DDP

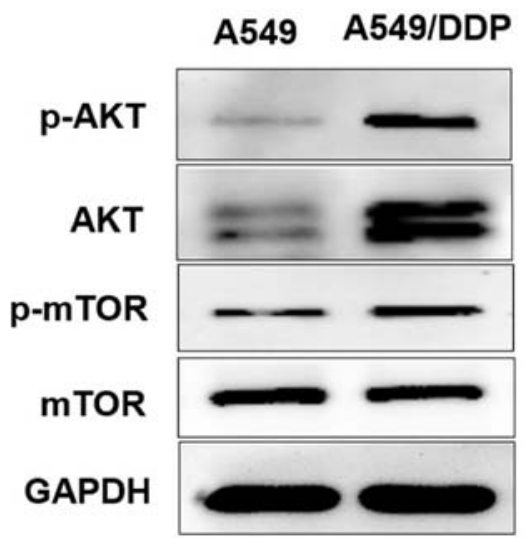

Figure 1. Characterization of A549 and A549/DDP cells. (A) A549 and A549/DDP cells were exposed to different concentrations of DDP (1-32 $\mu$ g/ml) for 24 h, and cell viability was determined by Cell Counting Kit-8 assay. The protein expression levels of (B) E-cadherin, vimentin, $\alpha$-SMA and (C) CIP2A, p-AKT, AKT, p-mTOR were measured using western blotting; E, epithelial; SMA, smooth muscle actin; p-mTOR, phosphorylated mammalian target of rapamycin; AKT, protein kinase B; DDP, cisplatin; CIP2A, cancerous inhibitor of protein phosphatase $2 \mathrm{~A}$; $\mathrm{IC}_{50}$, half maximal inhibitory concentration

was $33.36 \mu \mathrm{g} / \mathrm{ml}$. The DDP cytotoxicity in A549 cells was higher compared with A549/DDP cells.

In order to determine whether the EMT and CIP2A pathways are affected when A549 cells acquire resistance to DDP, the present study compared the levels of EMT markers and CIP2A, AKT, p-AKT, p-mTOR in A549 and A549/DDP cells. The results confirmed that the epithelial cell marker E-cadherin exhibited low expression, while the mesenchymal transition markers vimentin and $\alpha$-SMA were overexpressed in A549/DDP cells. The A549/DDP cell line exhibited the EMT phenotype (Fig. 1B). CIP2A and AKT, and p-AKT and p-mTOR were overexpressed in A549/DDP cells, while expression levels were decreased in A549 cells (Fig. 1C).

Inhibitory effects of PPI and PPVII on A549 and A549/DDP cells. Chemical structure of PPI and PPVII are shown in Fig. 2A. A549 and A549/DDP cells were seeded in 96-well plates for $24 \mathrm{~h}$ and then treated with different concentrations of PPI $(0.5-8 \mu \mathrm{g} / \mathrm{ml})$ and PPVII $(0.5-8 \mu \mathrm{g} / \mathrm{ml})$ for $24 \mathrm{~h}$. Cell viability was determined using a CCK- 8 assay and presented as a percentage of the control (Fig. 2B). The results revealed that PPI and PPVII both caused moderate cytotoxicity in A549 and A549/DDP cells in a dose-dependent manner.

Chemosensitizing effects of PPI and PPVII on A549/DDP cells. In order to determine whether PPI and PPVII can reverse the drug resistance of A549/DDP cells to DDP, the present study incubated cells with a range of doses of DDP in the absence or presence of $0.375 \mu \mathrm{g} / \mathrm{ml}$ PPI, $0.75 \mu \mathrm{g} / \mathrm{ml}$ PPI, $0.375 \mu \mathrm{g} / \mathrm{ml}$ PPVII and $0.75 \mu \mathrm{g} / \mathrm{ml}$ PPVII for $24 \mathrm{~h}$. Using the CCK-8 assay, it was revealed that PPI or PPVII in combination with DDP treatment drastically inhibited the cell viability of A549/DDP cells compared with DDP treatment alone; either PPI or PPVII with DDP treated cells demonstrated increased sensitivity to DDP at all concentrations (Fig. 3A and B). Furthermore, the $\mathrm{IC}_{50}$ value of the DDP plus $0.375 \mu \mathrm{g} / \mathrm{ml}$ PPI group $(6.17 \pm 0.88 \mu \mathrm{g} / \mathrm{ml})$ and DDP plus $0.75 \mu \mathrm{g} / \mathrm{ml}$ PPI group $(2.30 \pm 0.33 \mu \mathrm{g} / \mathrm{ml})$ was significantly decreased compared with the $\mathrm{IC}_{50}$ value of the DDP group $(33.42 \pm 4.05 \mu \mathrm{g} / \mathrm{ml}$; $\mathrm{P}<0.01 ; \mathrm{P}<0.01$; Table I). The $\mathrm{IC}_{50}$ value of the DDP plus $0.375 \mu \mathrm{g} / \mathrm{ml}$ PPVII group $(8.37 \pm 1.17 \mu \mathrm{g} / \mathrm{ml})$ and DDP plus $0.75 \mu \mathrm{g} / \mathrm{ml}$ PPVII group $(5.72 \pm 1.03 \mu \mathrm{g} / \mathrm{ml})$ were also significantly decreased compared with the $\mathrm{IC}_{50}$ value of the DDP group $(33.42 \pm 4.05 \mu \mathrm{g} / \mathrm{ml} ; \mathrm{P}<0.05 ; \mathrm{P}<0.01$, respectively; Table I). These results suggested that PPI and PPVII both have chemosensitizing effects on A549/DDP cells.

PPI and PPVII increases DDP-induced apoptosis in A549/DDP cells. Apoptosis is one of the major mechanisms responsible for DDP inhibiting cell proliferation (4) and failure of the apoptotic pathway may be the leading factor in DDP resistance (32). The present study subsequently investigated the roles of PPI and PPVII in DDP-induced apoptosis in A549/DDP cells using the Annexin V- FITC/PI apoptosis analysis (Fig. 4). The results demonstrated that the combination of DDP $(6 \mu \mathrm{g} / \mathrm{ml})$ with PPI $(0.75 \mu \mathrm{g} / \mathrm{ml})$ 
A

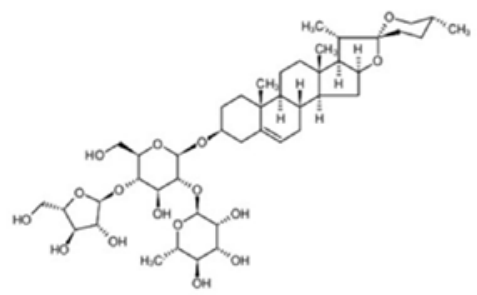

Polyphyllin I $\left(\mathrm{C}_{44} \mathrm{H}_{70} \mathrm{O}_{16}\right)$

B
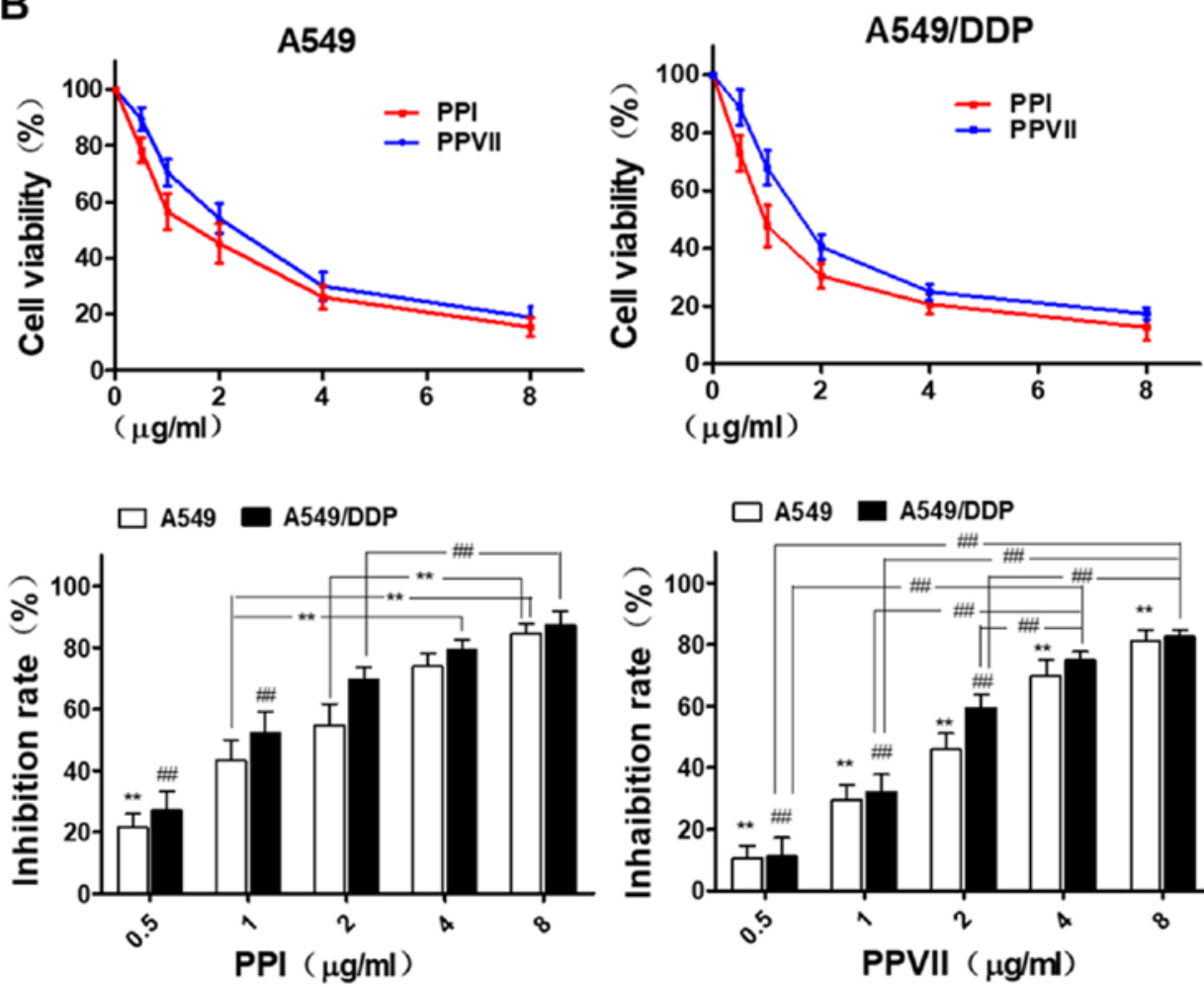

Figure 2. PPI and PPVII induce cytotoxicity in A549 and A549/DDP cells. (A) Chemical structure of PPI and PPVII. (B) A549 and A549/DDP cells were treated with different dose of PPI $(0.5-8 \mu \mathrm{g} / \mathrm{ml})$ and PPVII $(0.5-8 \mu \mathrm{g} / \mathrm{ml})$ for $24 \mathrm{~h}$, respectively. In A549 cells, the cell inhibition rate of $0.5 \mu \mathrm{g} / \mathrm{ml}$ PPI was significantly different from other concentration groups $\left({ }^{* *} \mathrm{P}<0.01\right) ; 1.0 \mu \mathrm{g} / \mathrm{ml}$ was significantly different from 4.0 and $8.0 \mu \mathrm{g} / \mathrm{ml}\left({ }^{* *} \mathrm{P}<0.01\right)$, and $2.0 \mu \mathrm{g} / \mathrm{ml}$ was significantly different from $8.0 \mu \mathrm{g} / \mathrm{ml}\left({ }^{* *} \mathrm{P}<0.01\right)$. As for A549/DDP cells, the cell inhibition rates of $0.5 \mu \mathrm{g} / \mathrm{ml} \mathrm{PPI}$ and $1.0 \mu \mathrm{g} / \mathrm{ml}$ were both significantly different from other concentration groups $\left({ }^{\# \#} \mathrm{P}<0.01\right)$, and $2.0 \mu \mathrm{g} / \mathrm{ml}$ was significantly different from $8.0 \mu \mathrm{g} / \mathrm{ml}\left({ }^{\# \#} \mathrm{P}<0.01\right)$. In A549 cells, there were significant differences in cell inhibition rates of PPVII among different concentration groups $\left({ }^{* *} \mathrm{P}<0.01\right)$; as for A549/DDP cells, there were significant differences among different concentration groups except for 4.0 and $8.0 \mu \mathrm{g} / \mathrm{ml}\left({ }^{\# \#} \mathrm{P}<0.01\right)$. PPI, Polyphyllin I; PPVII, polyphyllin VII; DDP, cisplatin.

significantly increased apoptosis rate $(57.2 \pm 5.2 \%)$ compared with DDP $(18.6 \pm 1.4 \%)$, or PPI alone $(29.9 \pm 4.3 \%$; $\mathrm{P}<0.01$; $\mathrm{P}<0.01$, respectively) and combination of DDP $(6 \mu \mathrm{g} / \mathrm{ml})$ with PPVII $(0.75 \mu \mathrm{g} / \mathrm{ml})$ also significantly increased apoptosis rate $(43.3 \pm 3.7 \%)$ compared with DDP $(18.6 \pm 1.4 \%)$, or PPVII alone $(16.7 \pm 1.8 \% ; \mathrm{P}<0.01 ; \mathrm{P}<0.01$, respectively). These results revealed that PPI and PPVII could promote DDP-induced apoptosis in A549/DDP cells.

PPI and PPVII enhance DDP-induced apoptosis via the p53 pathway and caspase-dependent pathway in A549/DDP cells. In order to determine the molecular mechanism underlying the way in which PPI and PPVII enhance the DDP-induced apoptosis in A549/DDP cells, the present study investigated the expression of key regulators, including p53, Bax, Bcl-2, PARP, cleaved-PARP, pro-caspase-3 and cleaved-caspase-3 protein, which are the most important apoptosis regulators.
The western blotting results demonstrated that DDP in combination with either PPI or PPVII treatment exhibited synergistic apoptosis-promoting effects in A549/DDP cells. Compared with the control group, DDP treatment upregulated the expression levels of $\mathrm{p} 53$, while the combination of DDP with either PPI or PPVII markedly enhanced this effect, which consequently upregulated the pro-apoptotic protein Bax and downregulated anti-apoptotic protein Bcl-2 expression compared with DDP treatment alone (Fig. 5A). The ratio of Bax to $\mathrm{Bcl}-2$ was enhanced, which led to the enhanced activation of PARP, as well as enhanced activation of caspase-3 and ultimately initiated enhanced cell apoptosis. A decrease in PARP and pro-caspase-3 was observed, as well as an increase in cleaved-PARP and cleaved-caspase-3 in DDP with either the PPI or PPVII treated group when compared with the DDP treated group (Fig. 5B). These results indicated that PPI and PPVII enhanced DDP-induced 

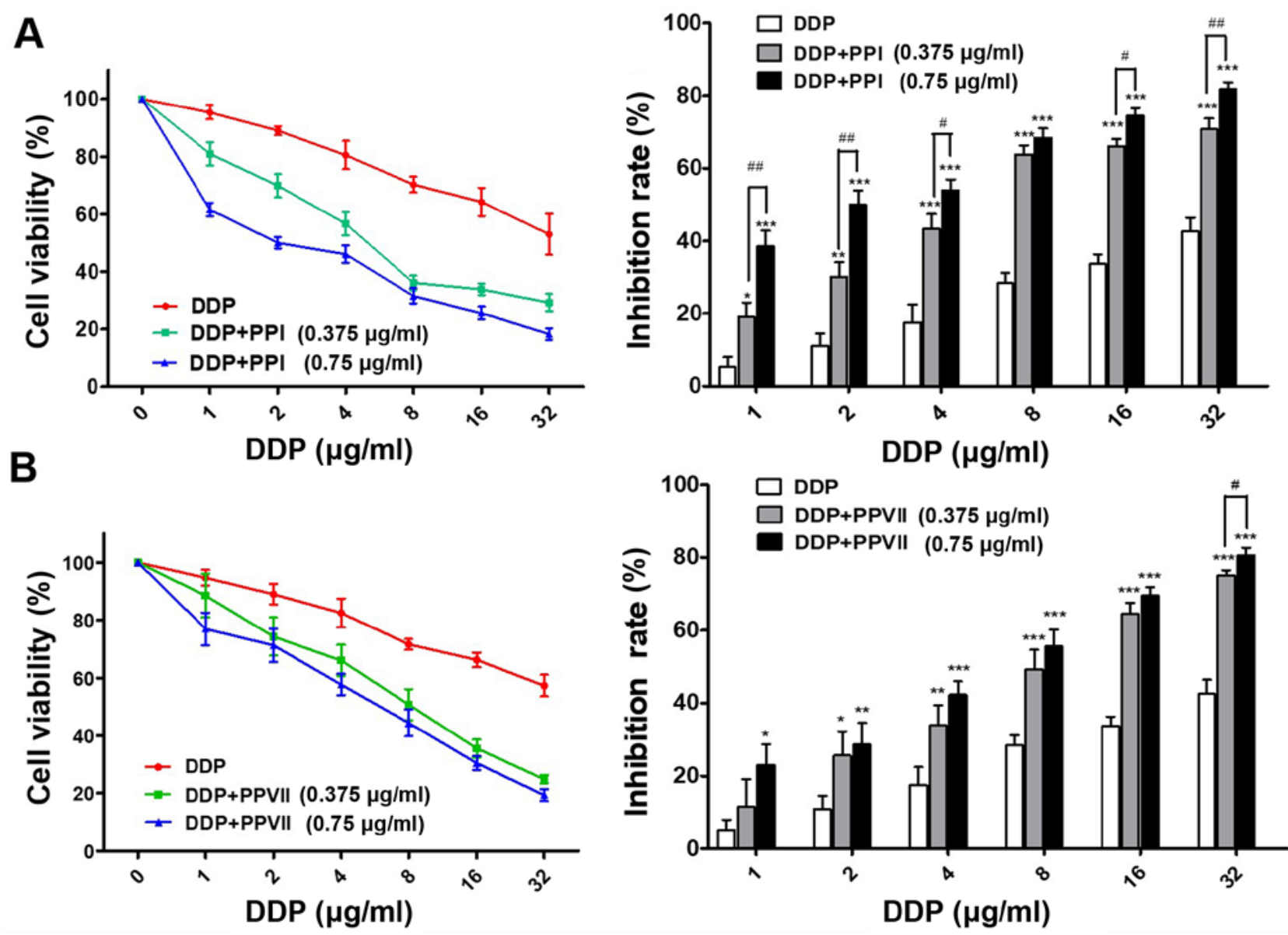

Figure 3. PPI and PPVII possess chemo-sensitizing effects on A549/DDP cells. (A) A549/DDP cells treated with indicated doses of DDP, or DDP plus either $0.375 \mu \mathrm{g} / \mathrm{ml}$ PPI or $0.75 \mu \mathrm{g} / \mathrm{ml}$ PPI, respectively for $24 \mathrm{~h}$. (B) A549/DDP cells treated with indicated doses of DDP, or DDP plus either $0.375 \mu \mathrm{g} / \mathrm{ml}$ PPVII or $0.75 \mu \mathrm{g} / \mathrm{ml}$ PPVII, respectively for $24 \mathrm{~h}$, cell viability was measured with Cell Counting Kit-8 assay. Data were presented as the mean \pm standard deviation. ${ }^{*} \mathrm{P}<0.05,{ }^{* *} \mathrm{P}<0.01$ and ${ }^{* * *} \mathrm{P}<0.001$ vs. DDP treated group. ${ }^{*} \mathrm{P}<0.05$ and ${ }^{\# \#} \mathrm{P}<0.01$. PPI, Polyphyllin I; PPVII, polyphyllin VII; DDP, cisplatin.

apoptosis via the p53 pathway and caspase-dependent pathway in A549/DDP cells.

PPI and PPVII reverse the EMT and suppress the CIP2A/AKT/mTOR pathway. It has previously been demonstrated that the A549/DDP cell line exhibited the EMT phenotype and that CIP2A, p-AKT, AKT and p-mTOR were overexpressed in A549/DDP cells (Fig. 1B and C). Therefore, the present study investigated the effect of PPI and PPVII on the EMT and CIP2A/AKT/mTOR pathway in A549/DDP cells. A549/DDP cells were incubated with DDP $(6 \mu \mathrm{g} / \mathrm{ml})$, PPI $(0.75 \mu \mathrm{g} / \mathrm{ml})$, PPVII $(0.75 \mu \mathrm{g} / \mathrm{ml})$ or DDP $(6 \mu \mathrm{g} / \mathrm{ml})$ in combination with either PPI $(0.75 \mu \mathrm{g} / \mathrm{ml})$ or PPVII $(0.75 \mu \mathrm{g} / \mathrm{ml})$ for $24 \mathrm{~h}$. Western blot analysis revealed that treatment with PPI and PPVII reversed the EMT in A549/DDP cells, as demonstrated by the upregulation of epithelial marker E-cadherin and downregulation of the mesenchymal markers vimentin and $\alpha$-SMA (Fig. 6A). DDP or PPI, PPVII treatment alone could all downregulate the expression of CIP2A and inhibit its downstream AKT phosphorylation and mTOR phosphorylation, while the combination of DDP with either PPI or PPVII enhanced these effects (Fig. 6B). PPI and PPVII could downregulate the AKT expression level, which may further suppress the AKT pathway. These results suggested that the combination of DDP with either PPI or PPVII had synergistic inhibitory effects on CIP2A/AKT/mTOR pathway in A549/DDP cells.

\section{Discussion}

DDP is the backbone of numerous mainstream chemotherapeutic regimens for advanced NSCLC. However, resistance to DDP in NSCLC is increasing and is a major limitation in its clinical application. Therefore, novel therapeutic strategies utilizing natural compounds may diminish the side-effects of chemotherapy agents. The present study identified the chemosensitizing effects of natural compounds PPI and PPVII in DDP-resistant NSCLC with the aim of gaining insight into the underlying molecular mechanism. The data revealed the chemosensitizing activities of PPI and PPVII in combination with DDP against A549/DDP cells.

As is already known, DDP acts by binding to DNA and inhibiting DNA synthesis, suppressing cell division and inducing apoptosis (33). Apoptosis of tumor cells is a key indicator for measuring the effectiveness of chemotherapy (34). One of the hallmarks of chemoresistance is evading apoptosis (33). In the present study, PPI and PPVII at low doses markedly enhanced the DDP-induced apoptosis effect in A549/DDP cells. The effects of PPI or PPVII on the expression of key apoptosis regulators were further investigated and the results revealed that PPI and PPVII treatment upregulated the expression of P53 and Bax, and downregulated Bcl-2 expression. The ratio of $\mathrm{Bax}$ to $\mathrm{Bcl}-2$ was enhanced, which led to the activation 
Table I. PPI and PPVII reduce the $\mathrm{IC}_{50}$ value of cisplatin in A549/DDP cells

\begin{tabular}{|c|c|c|c|}
\hline$\mu \mathrm{g} / \mathrm{ml}$ & DDP & DDP+PPI $(0.375 \mu \mathrm{g} / \mathrm{ml})$ & $\mathrm{DDP}+\mathrm{PPI}(0.75 \mu \mathrm{g} / \mathrm{ml})$ \\
\hline \multirow[t]{3}{*}{$\mathrm{IC}_{50}$ of DDP } & $33.42 \pm 4.05$ & $6.17 \pm 0.88^{b}$ & $2.30 \pm 0.33^{\mathrm{b}}$ \\
\hline & & DDP+PPVII $(0.375 \mu \mathrm{g} / \mathrm{ml})$ & DDP+PPVII $(0.75 \mu \mathrm{g} / \mathrm{ml})$ \\
\hline & & $8.37 \pm 1.17^{\mathrm{a}}$ & $5.72 \pm 1.03^{\mathrm{b}}$ \\
\hline
\end{tabular}

The $\mathrm{IC}_{50}$ was calculated using SPSS software (version 19.0). Values shown are the mean \pm standard deviation of quadruplicate determination. ${ }^{\mathrm{a}} \mathrm{P}<0.05$ and ${ }^{\mathrm{b}} \mathrm{P}<0.01$, vs. DDP treated group. PPI, Polyphyllin I; PPVII, polyphyllin VII; DDP, cisplatin; $\mathrm{IC}_{50}$, half maximal inhibitory concentration.

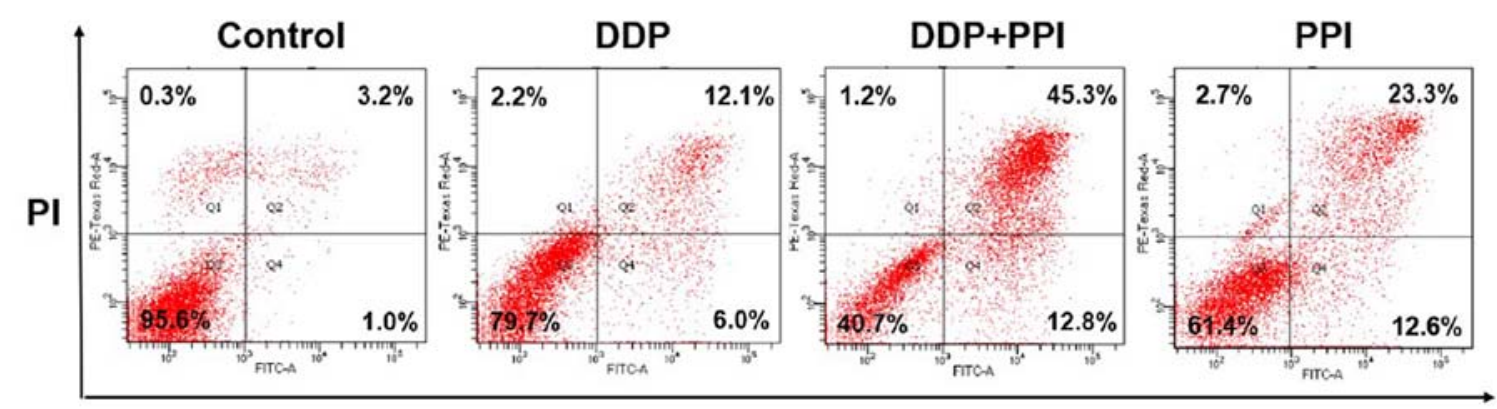

Annexin V-FITC

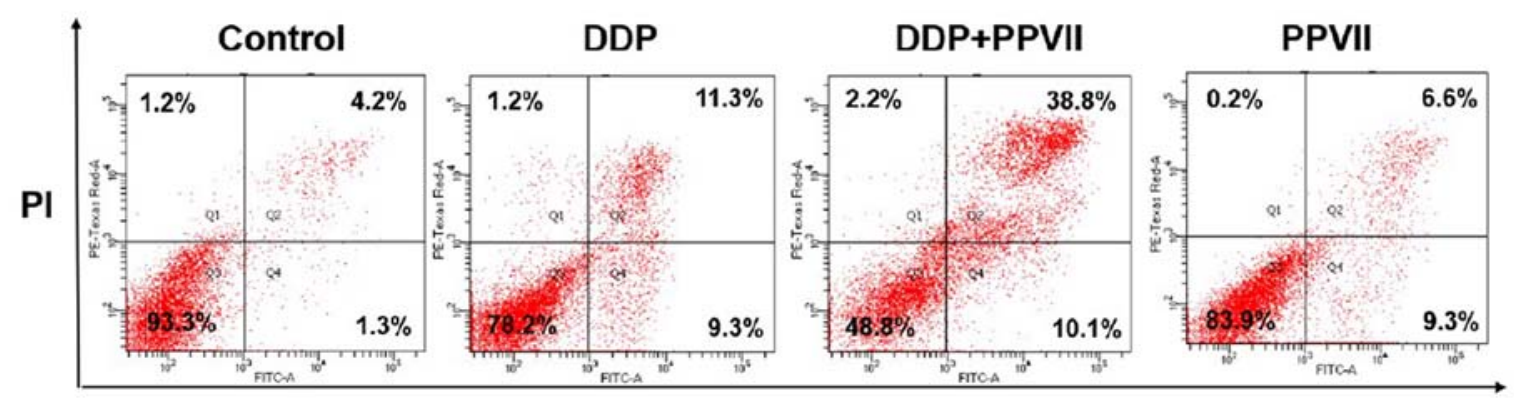

Annexin V-FITC
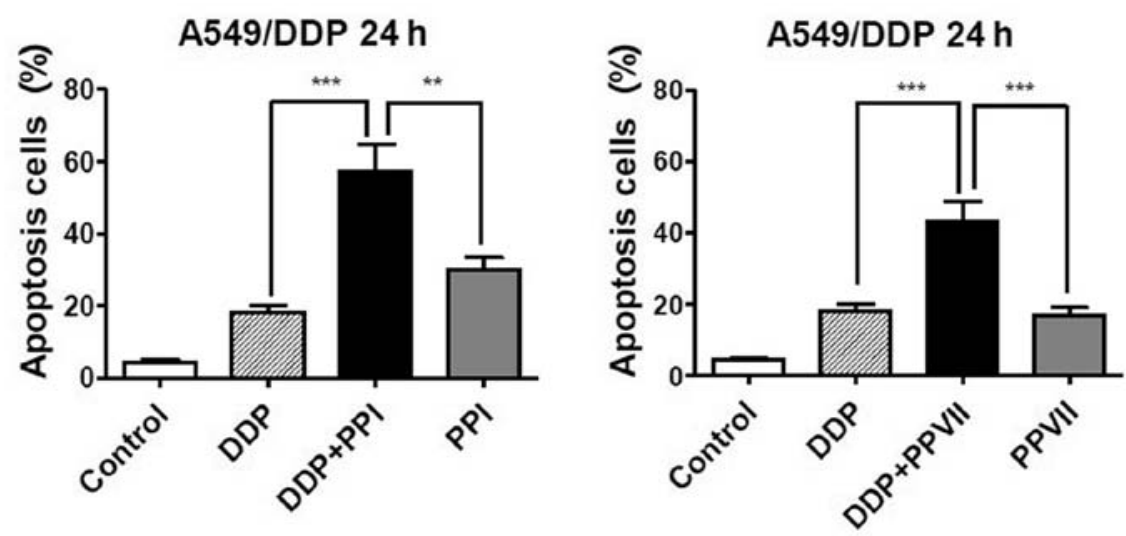

Figure 4. PPI and PPVII enhance DDP-induced apoptosis. A549/DDP cells were treated with DDP ( $6 \mu \mathrm{g} / \mathrm{ml})$, PPI $(0.75 \mu \mathrm{g} / \mathrm{ml})$, PPVII $(0.75 \mu \mathrm{g} / \mathrm{ml})$, or DDP $(6 \mu \mathrm{g} / \mathrm{ml})$ in combination with either PPI $(0.75 \mu \mathrm{g} / \mathrm{ml})$ or PPVII $(0.75 \mu \mathrm{g} / \mathrm{ml})$ for $24 \mathrm{~h}$, respectively. Apoptosis of cells was detected by Annexin V-FITC/PI staining and flow cytometry. The apoptotic percentage is shown as a bar graph. Data represents the mean \pm standard deviation of three independent experiments. ${ }^{* * *} \mathrm{P}<0.01$ and ${ }^{* * *} \mathrm{P}<0.001$. PPI, Polyphyllin I; PPVII, polyphyllin VII; DDP, cisplatin; FITC, fluorescein isothiocyanate; PI, propidium iodide.

of PARP, as well as activation of caspase-3. This was reflected by a decrease in PARP and an increase of cleaved-PARP and cleaved-caspase3, which ultimately initiated cell apoptosis. These results indicated that PPI and PPVII enhanced
DDP-induced apoptosis via p53 and the caspase-dependent pathway in A549/DDP cells. In addition, the results of the present study showed an interesting phenomenon that P53 was double- or multiple-banded and the adjacent bands are very 

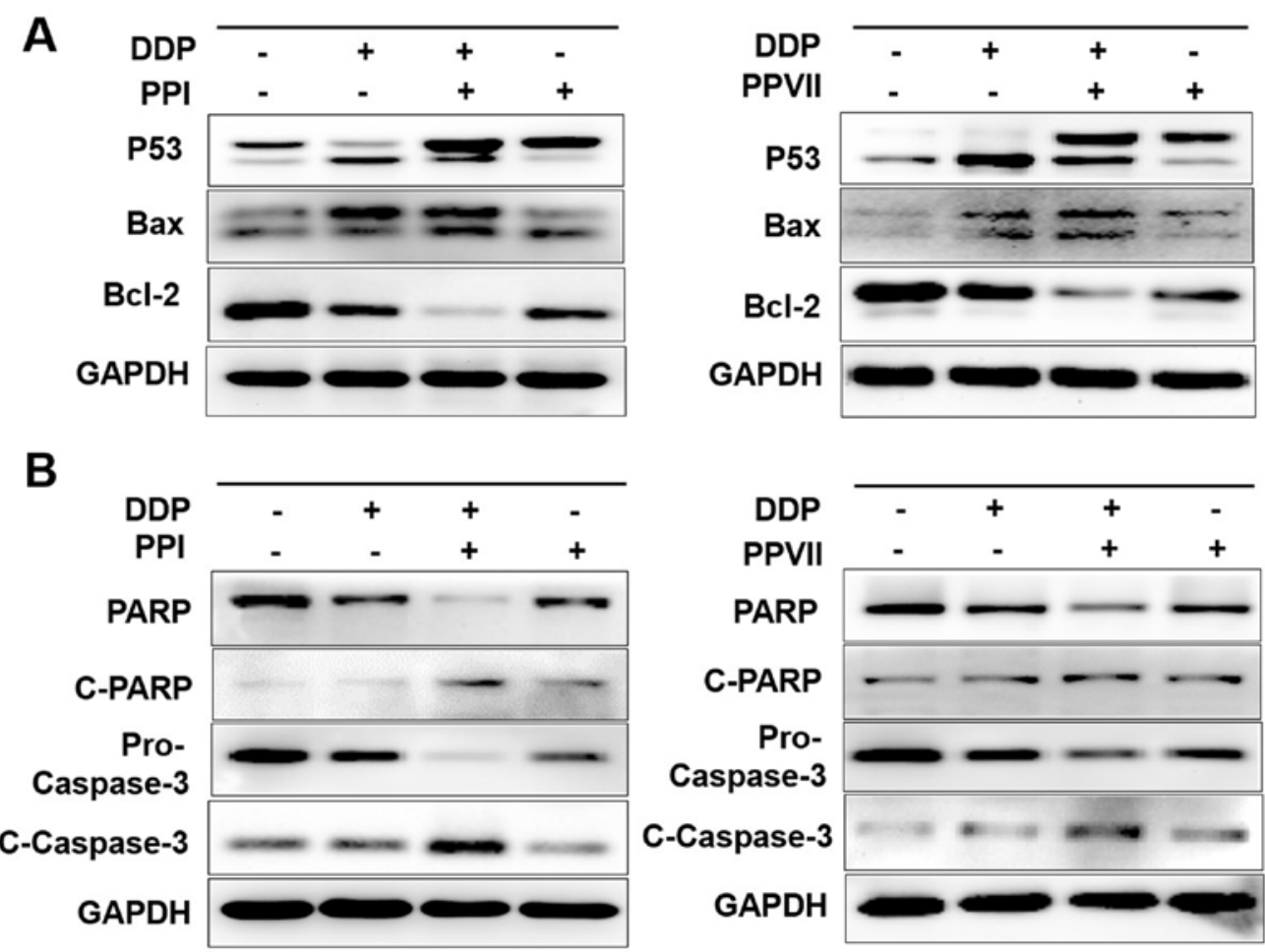

Figure 5. PPI and PPVII enhance DDP-induced apoptosis through the P53 pathway and caspases-dependent pathway. A549/DDP cells were treated with DDP $(6 \mu \mathrm{g} / \mathrm{ml})$, PPI $(0.75 \mu \mathrm{g} / \mathrm{ml})$, PPVII $(0.75 \mu \mathrm{g} / \mathrm{ml})$, or DDP $(6 \mu \mathrm{g} / \mathrm{ml})$ in combination with either PPI $(0.75 \mu \mathrm{g} / \mathrm{ml})$ or PPVII $(0.75 \mu \mathrm{g} / \mathrm{ml})$ for $24 \mathrm{~h}$, respectively. The protein expression levels of P53, Bax, Bcl-2 (A), PARP, C-PARP, pro-Caspase-3, C-Caspase-3 (B) were measured using western blotting. PPI, Polyphyllin I; PPVII, polyphyllin VII; DDP, cisplatin; C-PARP, cleaved-poly (ADP-ribose) polymerase 1.

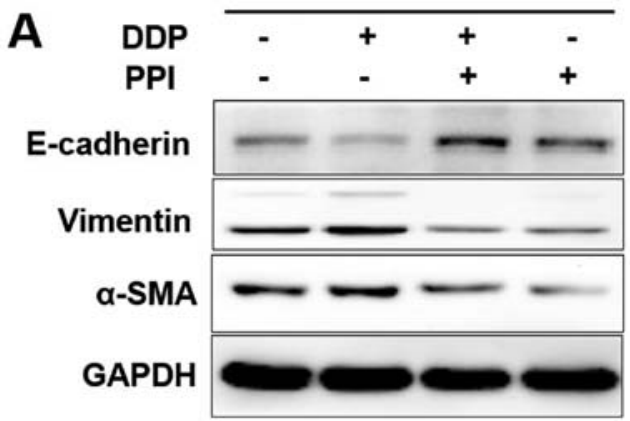

B

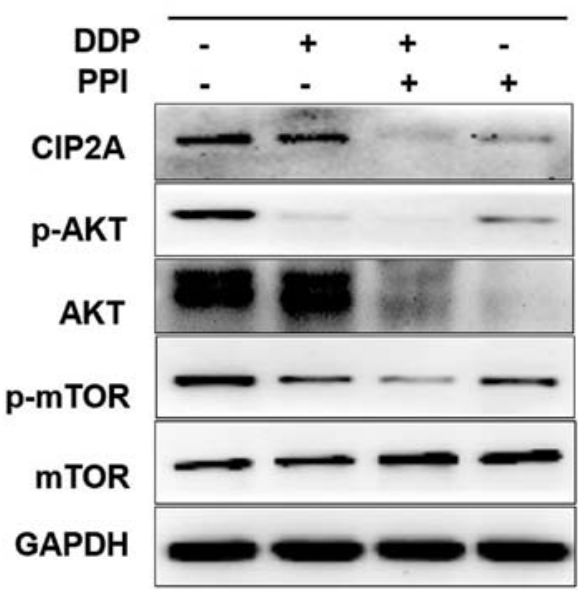

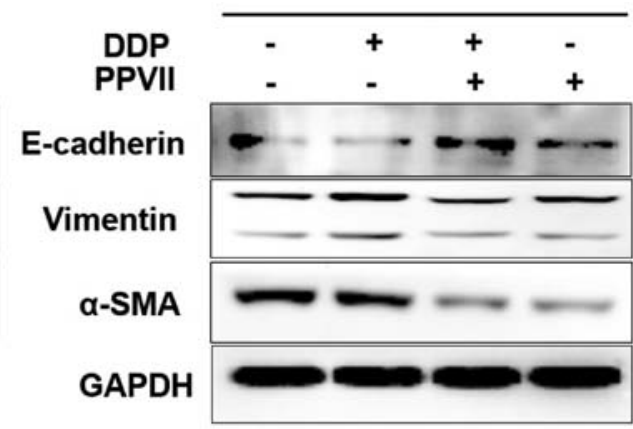

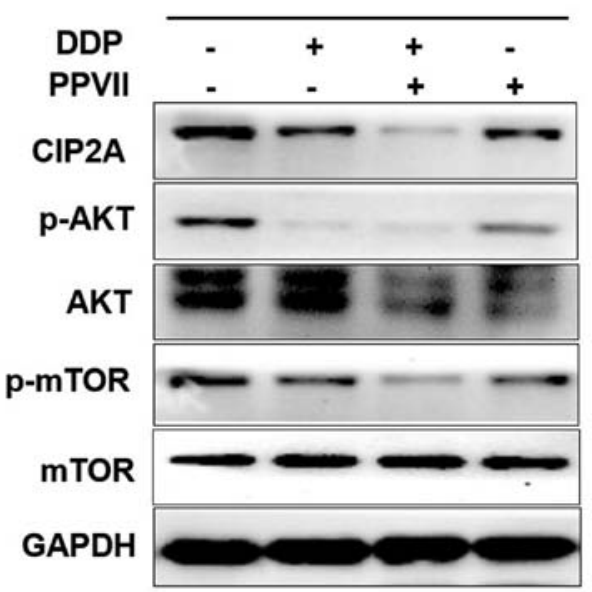

Figure 6. PPI and PPVII reverse EMT and suppress the CIP2A/AKT/mTOR pathway. A549/DDP cells were incubated with DDP $(6 \mu \mathrm{g} / \mathrm{ml}), \mathrm{PPI}(0.75 \mu \mathrm{g} / \mathrm{ml})$, PPVII $(0.75 \mu \mathrm{g} / \mathrm{ml})$, or DDP $(6 \mu \mathrm{g} / \mathrm{ml})$ in combination with either PPI $(0.75 \mu \mathrm{g} / \mathrm{ml})$ or PPVII $(0.75 \mu \mathrm{g} / \mathrm{ml})$ for $24 \mathrm{~h}$, then cells were harvested for further western blotting analysis. (A) The protein expression levels of E-cadherin, vimentin, $\alpha$-SMA in A549/DDP cells were measured. (B) The protein expression levels of CIP2A, p-AKT, AKT, p-mTOR, m-TOR were measured. PPI, Polyphyllin I; PPVII, polyphyllin VII; DDP, cisplatin; p-AKT, phosphorylated-protein kinase B; mTOR, mammalian target of rapamycin; CIP2A, cancerous inhibitor of protein phosphatase 2A; SMA, smooth muscle actin; E, epithelial. 
close to each other, even if multiple western blot experiments were repeated or switched to other P53 monoclonal antibodies. To solve this problem, the literature was consulted and possible explanations was investigated. P53 has many modifications, such as phosphorylation, ubiquitination, acetylation and methylation (35-37). According to the current experimental results, it is unclear what type of modification P53 underwent, but the present study hypothesizes that this is a valuable research direction and further experimental studies may be needed to determine which modification of P53 is mainly affected by these drugs.

A number of studies have demonstrated the association between EMT to the emergence of drug resistance (5-7), therefore ongoing research has been focused on determining ways to reverse the EMT with the aim of delaying or preventing drug resistance. CIP2A is a novel human oncoprotein that is overexpressed in NSCLC and associated with poor prognosis (8). CIP2A acts as an 'oncogenic nexus' to participate in multiple pathways, including the PI3K/AKT/mTOR, RAS/MEK/ERK and the Wnt/ $\beta$-catenin pathway (9). In addition, CIP2A cooperates with the oncogene $\mathrm{H}$-Ras via the MEK/ERK pathway to facilitate the EMT process (11). Furthermore, CIP2A expression is associated with DDP resistance $(15,16)$ and its downstream AKT/mTOR pathway plays an important role in mediating DDP resistance in lung cancer (15-17). The results from the present study revealed that the A549/DDP cell line exhibited the EMT phenotype and CIP2A, p-AKT, AKT and p-mTOR were overexpressed in A549/DDP cells. PPI and PPVII could reverse the EMT of A549/DDP cells, as evidenced by upregulation of the epithelial marker E-cadherin and downregulation of the mesenchymal markers vimentin and $\alpha$-SMA. DDP treatment alone could downregulate the expression of CIP2A and inhibit the downstream phosphorylation of AKT and mTOR, while the combination of DDP with either PPI or PPVII enhanced these effects. In addition, PPI and PPVII could downregulate the AKT expression level. These results suggest that the combination of DDP with either PPI or PPVII had synergistic inhibitory effects on the CIP2A/AKT/mTOR pathway in A549/DDP cells.

The function of CIP2A in apoptosis is not yet fully understood. A number of studies confirmed that CIP2A is involved in apoptosis and its depletion contributes to cell apoptosis in a number of different types of cancer $(14,38,39)$. Functional studies also confirmed the potential role of CIP2A depletion or downregulation in sensitizing cancer cells to several chemotherapeutic agents, including DDP $(17,40)$. In the present study, PPI and PPVII enhanced DDP-induced apoptosis via p53 and the caspase-dependent pathway; at the same time, PPI and PPVII had synergistic effects with DDP on CIP2A and its downstream AKT/mTOR signaling cascade in A549/DDP cells. As a tumor suppressor, p53 is activated in response to DNA-damaging stress, which can induce apoptosis in either transient or permanent cell cycle arrests. p53 has complicated interactions with CIP2A via PPP2R1A (9) and there is also abundant crosstalk between $\mathrm{p} 53$ and the AKT/mTOR signaling pathway, which could determine the choice of cell response to p53 (41) and requires further investigation.

The results of the present study determined that PPI and PPVII enhanced sensitivity to DDP, potentially through inducing increased apoptosis via the p53 pathway, reversing the EMT and suppressing the CIP2A/AKT/mTOR pathway in
A549/DDP cells. These data strongly suggested the potential beneficial effects of PPI and PPVII on patients suffering with DDP-resistant NSCLC.

\section{Acknowledgements}

Not applicable.

\section{Funding}

The present study was supported by the National Natural Science Foundation of China (grant no. 81473485) and the Natural Science Foundation of Shandong Province (grant no. 2014ZRE27321).

\section{Availability of data and materials}

All data generated or analyzed during this study are included in this published article.

\section{Authors' contributions}

FF and PC analyzed the data and wrote the manuscript. FF and PC performed the experiments. CW and YW assisted in preparing the experiments. WW designed the study. All authors have read and approved the final manuscript.

\section{Ethics approval and consent to participate}

Not applicable.

\section{Patient consent for publication}

Not applicable.

\section{Competing interests}

The authors declare that they have no competing interests.

\section{References}

1. Siegel RL, Miller KD and Jemal A: Cancer statistics, 2017. CA Cancer J Clin 67: 7-30, 2017.

2. Szejniuk WM, Robles AI, McCulloch T, Falkmer UGI and Røe OD: Epigenetic predictive biomarkers for response or outcome to platinum-based chemotherapy in non-small cell lung cancer, current state-of-art. Pharmacogenomics J 19: 5-14, 2019.

3. Cao L, Chen J, Ou B, Liu C, Zou Y and Chen Q: GAS5 knockdown reduces the chemo-sensitivity of non-small cell lung cancer (NSCLC) cell to cisplatin (DDP) through regulating miR-21/PTEN axis. Biomed Pharmacother 93:570-579, 2017.

4. Dasari S, Tchounwou PB: Cisplatin in cancer therapy: Molecular mechanisms of action. Eur J Pharmacol 740: 364-378, 2014.

5. Du B and Shim JS: Targeting epithelial-mesenchymal transition (EMT) to overcome drug resistance in cancer. Molecules 21: E965, 2016

6. Shibue T and Weinberg RA: EMT, CSCs, and drug resistance: The mechanistic link and clinical implications. Nat Rev Clin Oncol 14: 611-629, 2017.

7. Song Y, Ye M, Zhou J, Wang Z and Zhu X: Targeting E-cadherin expression with small molecules for digestive cancer treatment. Am J Transl Res 11: 3932-3944, 2019.

8. Liu Z, Ma L, Wen ZS, Hu Z, Wu FQ, Li W, Liu J and Zhou GB: Cancerous inhibitor of PP2A is targeted by natural compound celastrol for degradation in non-small-cell lung cancer. Carcinogenesis 35: 905-914, 2014. 
9. De P, Carlson J, Leyland-Jones B and Dey N: Oncogenic nexus of cancerous inhibitor of protein phosphatase 2A (CIP2A): An oncoprotein with many hands. Oncotarget 5: 4581-4602, 2014.

10. Tang M, Shen JF, Li P, Zhou LN, Zeng P, Cui XX, Chen MB and Tian Y: Prognostic significance of CIP2A expression in solid tumors: A meta-analysis. PLoS One 13: e0199675, 2018.

11. Wu Y, Gu TT and Zheng PS: CIP2A cooperates with H-Ras to promote epithelial mesenchymal transition in cervical-cancer progression. Cancer Lett 356: 646-655, 2015.

12. Lin YC, Chen KC, Chen CC, Cheng AL and Chen KF. CIP2A-mediated Akt activation plays a role in bortezomibinduced apoptosis in head and neck squamous cell carcinoma cells. Oral Oncol 48: 585-593, 2012.

13. Yu HC, Chen HJ, Chang YL, Liu CY, Shiau CW, Cheng AL and Chen KF: Inhibition of CIP2A determines erlotinib-induced apoptosis in hepatocellular carcinoma. Biochem Pharmacol 85: $356-366,2013$

14. Xu P, Yao J, He J, Zhao L, Wang X, Li Z and Qian J: CIP2A down regulation enhances the sensitivity of pancreatic cancer cells to gemcitabine. Oncotarget 7: 14831-14840, 2016.

15. Zhang X, Xu B, Sun C, Wang L and Miao X: Knockdown of CIP2A sensitizes ovarian cancer cells to cisplatin: An in vitro study. Int J Clin Exp Med 8: 16941-16947, 2015.

16. Gao F, Wang X, Chen S, Xu T, Wang X, Shen Y, Dong F, Zhong S and Shen Z: CIP2A depletion potentiates the chemosensitivity of cisplatin by inducing increased apoptosis in bladder cancer cells. Oncol Rep 40: 2445-2454, 2018.

17. Liu LZ, Zhou XD, Qian G, Shi X, Fang J and Jiang BH: AKT1 amplification regulates cisplatin resistance in human lung cance cells through the mammalian target of rapamycin/p70S6K1 pathway. Cancer Res 67: 6325-6332, 2017.

18. Ho JW, Leung YK and Chan CP: Herbal medicine in the treatment of cancer. Curr Med Chem Anticancer Agents 2: 209-214, 2002.

19. Shi YM, Yang L, Geng YD, Zhang C and Kong LY: Polyphyllin I induced-apoptosis is enhanced by inhibition of autophagy in human hepatocellular carcinoma cells. Phytomedicine 22: 1139-49, 2015.

20. Gu L, Feng J, Zheng Z, Xu H and Yu W: Polyphyllin I inhibits the growth of ovarian cancer cells in nude mice. Oncol Lett 12 : 4969-4974, 2016.

21. Chang J, Li Y, Wang X, Hu S, Wang H, Shi Q, Wang Y and Yang Y: Polyphyllin I suppresses human osteosarcoma growth by inactivation of $\mathrm{Wnt} / \beta$-catenin pathway in vitro and in vivo Sci Rep 7: 7605, 2017.

22. Dong R, Guo J, Zhang Z, Zhou Y and Hua Y: Polyphyllin I inhibits gastric cancer cell proliferation by downregulating the expression of fibroblast activation protein alpha (FAP) and hepatocyte growth factor (HGF) in cancer-associated fibroblasts Biochem Biophys Res Commun 497: 1129-1134, 2018.

23. Yang Q, Chen W, Xu Y, Lv X, Zhang M and Jiang H: Polyphyllin I modulates MALAT1/STAT3 signaling to induce apoptosis in gefitinib-resistant non-small cell lung cancer. Toxicol Appl Pharmacol 356: 1-7, 2018.

24. Zhang C, Jia X, Bao J, Chen S, Wang K, Zhang Y, Li P, Wan JB, $\mathrm{Su} \mathrm{H}$, Wang Y, et al: Polyphyllin VII induces apoptosis in HepG2 cells through ROS-mediated mitochondrial dysfunction and MAPK pathways. BMC Complement Altern Med 16: 58, 2016.

25. Lin Z, Liu Y, Li F, Wu J,Zhang G, Wang Y, Lu L and Liu Z: Anti-lung cancer effects of polyphyllin vi and vii potentially correlate with apoptosis in vitro and in vivo. Phytother Res 29: 1568-1576, 2015.

26. Hsieh MJ, Chien SY, Lin JT, Yang SF and Chen MK: Polyphyllin $\mathrm{G}$ induces apoptosis and autophagy cell death in human oral cancer cells. Phytomedicine 23: 1545-1554, 2016.
27. Cai X, Guo L, Pei F, Chang X and Zhang R: Polyphyllin G exhibits antimicrobial activity and exerts anticancer effects on human oral cancer OECM-1 cells by triggering G2/M cell cycle arrest by inactivating cdc25C-cdc2. Arch Biochem Biophys 644: 93-99, 2018.

28. Han W, Hou G and Liu L: Polyphyllin I (PPI) increased the sensitivity of hepatocellular carcinoma HepG2 cells to chemotherapy. Int J Clin Exp Med 8: 20664-20669, 2015.

29. Al Sawah E, Marchion DC, Xiong Y, Ramirez IJ, Abbasi F, Boac BM, Bush SH, Bou Zgheib N, McClung EC, Khulpateea BR, et al: The Chinese herb polyphyllin D sensitizes ovarian cancer cells to cisplatin-induced growth arrest. J Cancer Res Clin Oncol 141: 237-42, 2015.

30. Lou W, Chen Y, Zhu KY, Deng H, Wu T and Wang J: Polyphyllin I overcomes EMT-associated resistance to erlotinib in lung cancer cells via IL-6/STAT3 Pathway Inhibition. Biol Pharm Bull 40: 1306-1313, 2017.

31. Li Y, Fan L, Sun Y, Miao X, Zhang F, Meng J, Han J, Zhang D, Zhang R, Yue Z and Mei Q: Paris saponin VII from trillium tschonoskii reverses multidrug resistance of Adriamycin resistant MCF-7/ADR cells via P-glycoprotein inhibition and apoptosis augmentation. J Ethnopharmacol 154: 728-734, 2014.

32. Wang H, Fei Z and Jiang H: Polyphyllin VII increases sensitivity to gefitinib by modulating the elevation of P21 in acquired gefitinib resistant non-small cell lung cancer. J Pharmacol Sci 134: 190-196, 2017.

33. Galluzzi L, Senovilla L, Vitale I, Michels J, Martins I, Kepp O, Castedo M and Kroemer G: Molecular mechanisms of DDP resistance. Oncogene 31: 1869-1883, 2012.

34. Liu H, Li P, Li B, Sun P, Zhang J, Wang B and Jia B: RKIP promotes Cisplatin-induced gastric cancer cell death through NF- $\mathrm{BB} /$ Snail pathway. Tumour Biol 36: 1445-1153, 2015.

35. Xu Y: Regulation of p53 responses by post-translational modifications. Cell Death Differ 10: 400-403, 2003.

36. Bode AM and Dong Z: Post-translational modification of p53 in tumorigenesis. Nat Rev Cancer 4: 793-805, 2004.

37. Park JH, Yang SW, Park JM, Ka SH, Kim JH, Kong YY, Jeon YJ, Seol JH and Chung $\mathrm{CH}$ : Positive feedback regulation of $\mathrm{p} 53$ transactivity by DNA damage-induced ISG15 modification. Nat Commun 7: 12513, 2016.

38. Liu X, Duan C, Ji J, Zhang T, Yuan X, Zhang Y, Ma W, Yang J, Yang L, Jiang Z, et al: Cucurbitacin B induces autophagy and apoptosis by suppressing CIP2A/PP2A/mTORC1 signaling axis in human cisplatin resistant gastric cancer cells. Oncol Rep 38: 271-278, 2017.

39. Chao TT, Wang CY, Chen YL, Lai CC, Chang FY, Tsai YT, Chao CH, Shiau CW, Huang YC, Yu CJ and Chen KF: Afatinib induces apoptosis in NSCLC without EGFR mutation through Elk-1-mediated suppression of CIP2A. Oncotarget 6: 2164-2179, 2015.

40. Xu P, Yao J, He J, Zhao L, Wang X, Li Z and Qian J: CIP2A down regulation enhances the sensitivity of pancreatic cancer cells to gemcitabine. Oncotarget 7: 14831-14840, 2016.

41. Duan L and Maki CG: The IGF-1R/AKT pathway determines cell fate in response to p53. Transl Cancer Res 5: 664-675, 2016.

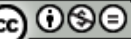

This work is licensed under a Creative Commons Attribution-NonCommercial-NoDerivatives 4.0 International (CC BY-NC-ND 4.0) License. 